\section{UJMM

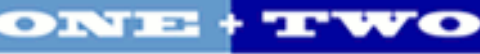

Volume $10 \mid 2020$ Spring 2020

\section{Undergraduate Journal of Mathematical} Modeling: One + Two

2020

\title{
An Exploration of Wind Energy
}

Bianca De Haan

University of South Florida

Advisors:

Arcadii Grinshpan, Mathematics and Statistics

Tracy Dawson, Marine Science Center, Ponce Inlet, Florida

Problem Suggested By: Tracy Dawson

Follow this and additional works at: https://digitalcommons.usf.edu/ujmm

Part of the Mathematics Commons

UJMM is an open access journal, free to authors and readers, and relies on your support: Donate Now

\section{Recommended Citation}

De Haan, Bianca (2020) "An Exploration of Wind Energy," Undergraduate Journal of Mathematical Modeling: One + Two: Vol. 10: Iss. 2, Article 4.

DOI: https://doi.org/10.5038/2326-3652.10.2.4917

Available at: https://digitalcommons.usf.edu/ujmm/vol10/iss2/4 


\title{
An Exploration of Wind Energy
}

\begin{abstract}
Wind energy is renewable energy extrapolated from the wind that has the potential to revolutionize our power supply in the near future as fossil fuels become outdated. Wind turbines capture the energy as the wind spins the blades of the turbine, transforming wind energy into mechanical energy and then into electrical energy through a generator. One of the techniques utilized to understand wind energy is to manipulate various variables in the formula for wind power. These variables such as the power coefficient, wind velocity, number and length of blades are explored to find its optimal value. The variable of turbine efficiency is explored by deriving Betz limit from the known physics formulas, in order to understand one of the limitations of the wind energy formula. It can be deduced that turbine design is also valuable for the efficiency of wind turbines. This is where the length and the number of blades are explored through the tip speed ratio in order to understand how to achieve maximum efficiency.
\end{abstract}

\section{Keywords}

wind turbine, power coefficient, Betz limit, tip speed ratio

\section{Creative Commons License}

(c)

This work is licensed under a Creative Commons Attribution-Noncommercial-Share Alike 4.0 License. 


\section{PROBLEM STATEMENT}

The problem is to investigate potential renewable energy alternatives in order to supply power to the Marine Science Center located in Ponce Inlet, Florida. Choose the most likely candidate and explore efficiency and power output by manipulating various variables, then compare to the local conditions.

\section{MOTIVATION}

The decreasing supply of fossil fuels and the harmful, long-lasting effects they pose on the environment makes it crucial to find alternative and sustainable energy sources. Currently and previously, fossil fuels have dominated the power supply despite the many environmental risks such as emitting greenhouse gases, contributing to climate change, releasing carcinogenic substances and other toxic by-products such as air and water pollution. However, with the decreasing supply of fossil fuels and rising energy consumption, many renewable sources of energy are being researched and utilized.

Capturing wind energy, through the use of wind turbines, is a very achievable source of energy that is becoming more commonplace throughout the world with various wind farms being built. They can be built almost anywhere with substantial wind and land area, and they do not emit any pollutants or harm the environment. The cost of wind turbines is high to start up, but maintenance cost is low compared to that of fossil fuel plants. For example, countries such as Portugal, Spain and Ireland have 35\% dependability on wind energy ("Renewable Energy and Electricity").

Investigating the efficiency and understanding various variables that effect wind energy output is important in order to maximize power output per turbine. Perfecting efficiency also 
helps to keep up with today's ever-increasing energy demands, although wind turbines have come a long way already. The first ever turbine built in 1888 produced twelve kilowatt hours per year, while today's average turbines produce around six million kilowatt hours per year. By improving designs and pushing towards maximum efficiency, wind turbines will be able to produce even more energy in the future. This is important for a future of clean, renewable energy sources and a healthy environment ("Renewable Energy and Electricity").

Concerning the scope of this project, the Marine Science Center in Ponce Inlet, Florida is interested in investing in renewable energy sources in order to sustain their main building. For this problem, wind energy is chosen because it is one of the most accessible forms of renewable energy when compared to other alternatives (such as solar power, tidal power, or wave power).

\section{MATHEMATICAL DESCRIPTION AND SOLUTION APPROACH}

The main equation that is being used is the following wind power formula. It relates various variables to the power output of a wind turbine (see, for example, Blackwood's work (2016)):

$$
P=p C_{p} A V^{3} / 2
$$

In formula (1), $P$ represents power measured in watts, $p$ is air density measured in $\mathrm{kg} / \mathrm{m}^{3}, C_{p}$ stands for maximum power coefficient (limited by Betz limit, or a theoretical limit $\approx 0.593$ ), $A$ stands for swept rotor area measured in $\mathrm{m}^{2}$, and $V$ is velocity in $\mathrm{m} / \mathrm{s}$.

In order to optimize the wind energy gathered from a single turbine, each variable must be explored for optimal performance. The maximum power coefficient $C_{p}$ is limited by Betz limit. Fundamentally, this maximum coefficient could never reach $100 \%$ (or 1), because then wind would enter the turbine and simply stop, which is not logical. Therefore, there must be a limit to this value, to account for the wind that is not transferred into power but passes through the blades of the turbine (Carriveau). 
The proof begins with the equation for the mass of the air passing through the rotor for one second, given below:

$$
m=p A\left(v_{1}+v_{2}\right) / 2
$$

In equation (2), $p$ stands for air density; $A$ is swept rotor area, $v_{1}$ for wind velocity before the wind turbine and $v_{2}$ for the wind velocity after the turbine. Deducted from Newton's second law, the following equation represents the power extrapolated from the motor of the turbine based off the mass and the drop of wind speed as it passes through the turbine:

$$
P=m\left(v_{1}^{2}-v_{2}^{2}\right) / 2
$$

Utilizing formula (2), $m$ can be substituted into equation (3) in order to achieve an equation for the power extrapolated from the wind:

$$
P=\left(v_{1}^{2}-v_{2}^{2}\right)\left(v_{1}+v_{2}\right) p A / 4
$$

Equation (4) can be compared to the theoretical formula for wind energy without a maximum power coefficient (with the wind turbine operated at $100 \%$ efficiency). This value will be $P_{0}$ in equation (5):

$$
P_{0}=p v_{1}^{3} A / 2
$$

The ratio between the power that is extracted from the wind and the theoretical maximum-efficiency power is $P / P_{0}$, in equation (6):

$$
P / P_{0}=\frac{\left(v_{1}^{2}-v_{2}^{2}\right)\left(v_{1}+v_{2}\right)}{2 v_{1}^{3}}
$$

The variables for air density, $p$, and the rotor swept area, $A$, are cancelled out in both equations. Equation (7) is generated by equation (6), where $v_{2} / v_{1}$ is substituted by $x$ :

$$
P / P_{0}=\left(1-x^{2}+x-x^{3}\right) / 2
$$


From formula (7), the derivative needs to be found in order to maximize the ratio, and therefore, find the theoretical maximum to wind turbine efficiency:

$$
\left(P / P_{0}\right)^{\prime}=\left(-2 x+1-3 x^{2}\right) / 2
$$

By simplifying equation (8) and setting it to zero, we find the critical points. We also undo our substitution and set $x$ to $v_{2} / v_{1}$ :

$$
\left(P / P_{0}\right)^{\prime}=\left(1+\frac{v_{2}}{v_{1}}\right)\left(1-3 \frac{v_{2}}{v_{1}}\right) / 2
$$

By setting the individual factors in (9) to zero, we arrive to two solutions:

$v_{2}=-v_{1}$ and $\frac{v_{2}}{v_{1}}=\frac{1}{3}$. The first solution is disregarded because it is impossible for the wind speed before and after the turbine to be in opposite directions. The second solution states that to maximize the efficiency of the wind turbine by maximizing power, the velocity after the turbine must be equal to a third of velocity before the turbine. By substituting $x=1 / 3$ into equation (7), the maximum power coefficient can be solved for:

$$
\begin{gathered}
P / P_{0}=\left(1-x^{2}+x-x^{3}\right) / 2, \\
x=\frac{1}{3} \rightarrow P / P_{0}=\left[1-\left(\frac{1}{3}\right)^{2}+\left(\frac{1}{3}\right)-\left(\frac{1}{3}\right)^{3}\right] / 2=\frac{16}{27} \approx 0.59259 .
\end{gathered}
$$

The graph below also helps visualizing these results. 


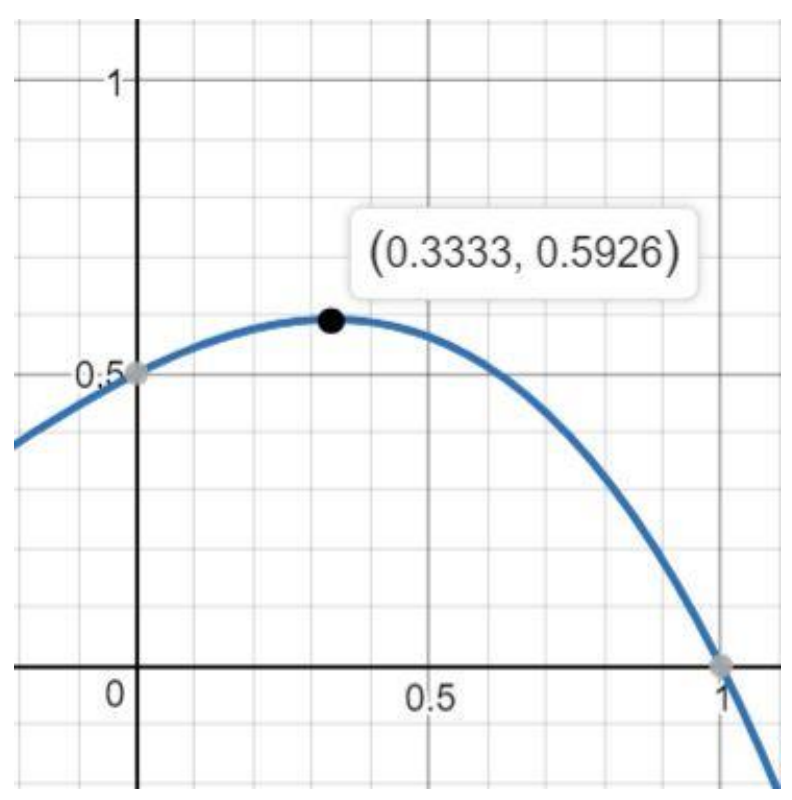

This theoretical value of $59.3 \%$ is known at Betz limit (Carriveau). It demonstrates that when designing a wind turbine, the goal is to have wind leave the turbine at one-third of the velocity it entered at. In this ideal scenario, power output is maximized. Therefore wind turbines should be designed and tested taking into account these circumstances.

One can examine the other variables that affect the power output of a wind turbine in formula (1): $P=p C_{p} A V^{3} / 2$. The other variables that can be changed or altered are the velocity of the wind and the rotor swept area. As velocity increases, so does power, however, a wind turbine would undergo stress and structurally fail under high velocities due to physical constraints. When this occurs, most wind turbines are equipped with technology that 'furl' the turbine or send an opposing force in the rotor to slow down the blades to prevent damage to the turbine. 


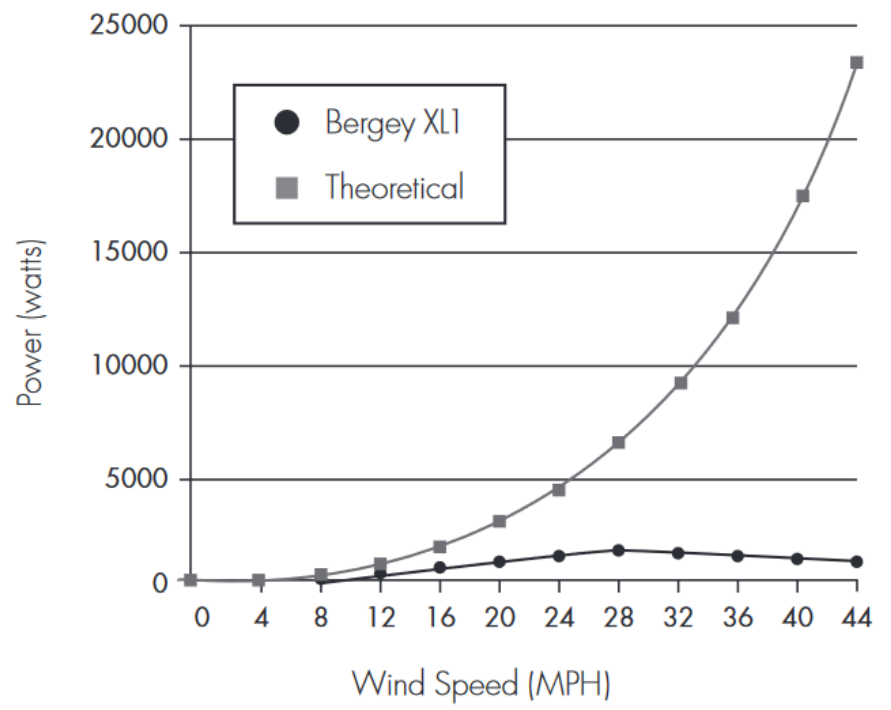

This graph illustrates the actual power generated by the Bergey XL1, a $1 \mathrm{~kW}$ wind turbine, compared to the theoretical power that can be outputted according to Betz limit. As seen, power output begins to decrease after its max power output at $28 \mathrm{MPH}$. The graph below also demonstrates a similar phenomenon ("Small Wind Turbines").

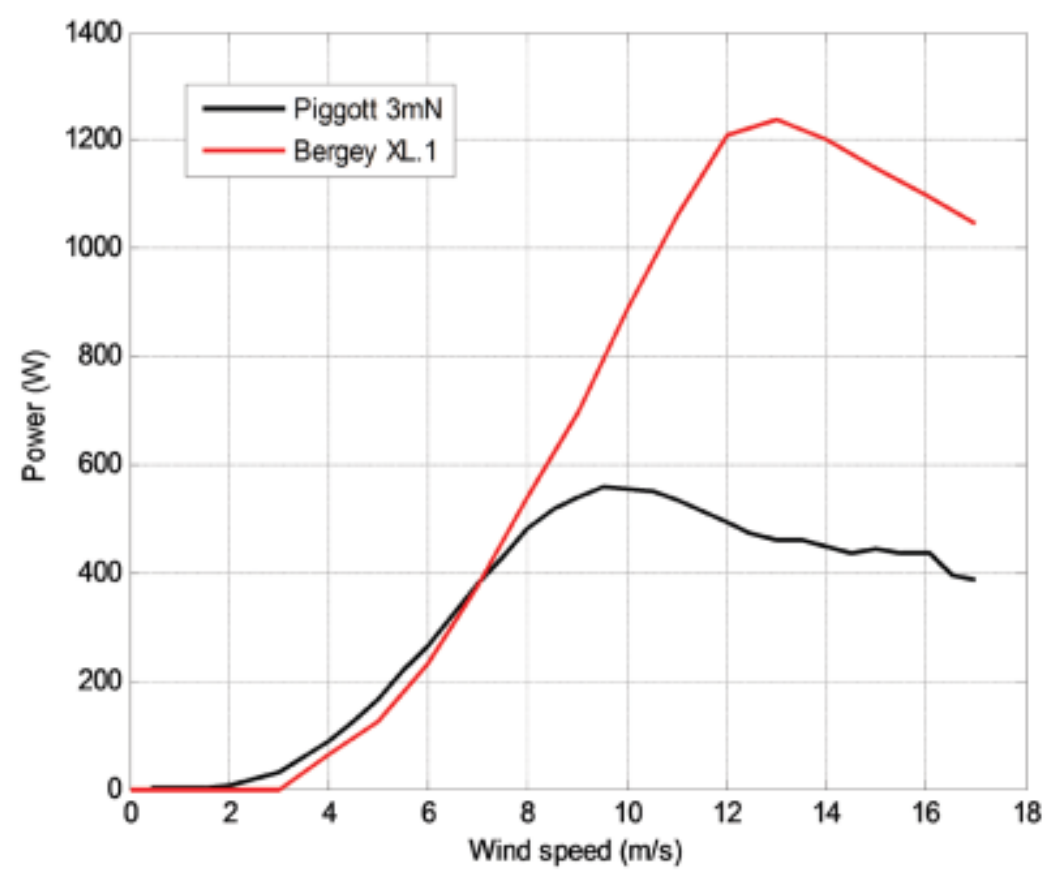


In both wind turbine models graphed above, after the turbine reaches max power output, the power output begins to decrease as wind velocity increases. The optimal velocity is determined by a variable called the Tip-Speed-Ratio (TSR), which is also determined by Betz Law (Bakırc1, p. 1130). This theory states that it is ideal for blades to travel at such a speed when they do not travel in the turbulence of the last blade but are fast enough to capture the most amount of energy possible from the wind. Optimizing this value is important for optimizing efficiency, in order to determine how many blades are optimal for different wind speeds. This can later be related to the scope of this exploration.

$$
\text { Tip Speed Ratio }=\lambda=\frac{\text { speed of rotor tip }}{\text { wind speed }}=\frac{v}{V}=\frac{\omega R}{V}
$$

Where $\omega$ is the variable for angular velocity, while $R$ is blade length. The following is the formula for the period of the rotor, where $B$ measures blade number:

$$
\text { Period of the rotor }=\frac{2 \pi}{\omega B}
$$

For optimum efficiency, the period should be equivalent to the disturbed wind turn in its original state. This is given below:

$$
\text { Disturbed Wind Turn }=\frac{S}{V}=\frac{\text { Length of air stream of the rotor }}{\text { Velocity of the wind on the rotor }}=\frac{R / 2}{V}
$$

Setting these two equations equal gives the following equation:

$$
\frac{2 \pi}{\omega B}=\frac{R}{2 V}
$$

Simplifying this equation results in: $R \omega / V=4 \pi / B=$ Optimum Tip Speed Ratio

This optimum tip speed ratio suggests that for varying wind velocities, there is an optimal number of blades. From the derived expression above, it can be determined that fewer blades are necessary for larger tip speed ratios, which implies that fewer blades need high wind velocities to 
reach maximum efficiency (Bakırc1, p. 1130). The opposite is also true. This is where for maximum efficiency, the more blades there are the lower speeds the wind turbine operates at. Using three months is often the middle ground for an optimal tip speed ratio and energy output. This number also ideally provides a good balance between stability and high energy yield (Kerrigan).

Concerning the last variable that can affect power output of a wind turbine, the rotor swept area is concurrent and it is only affected by the length of the blades. So far, according to experts, the higher the hub height of the rotor and the larger the length of the blades, the higher energy yield the wind turbine provides (Deign). There have been predictions of a potential ceiling for this theory; however, it has not been reached yet with current wind turbines (Deign). New turbines are being built bigger than the previous ones in order to capitalize this and they are only constrained financially (Deign).

Altogether, the power output of a wind turbine is affected by various, controllable factors that can be optimized for higher efficiency. With further research, designs, and funding, wind power has the potential to make a huge contribution to our increasing energy demands and for the demands of the future.

\section{DISCUSSION}

In the local scope of this exploration, it is unlikely that wind energy can aid the Marine Science Center, because building a small wind turbine is not efficient. Larger wind turbines in optimal areas with good wind conditions are more efficient to capture wind power ("Small Wind Turbines"). Additionally, there is not enough funding within the Marine Science Center to cover the start-up cost of building a turbine. Other problems exist such that off-coast turbines are more effective than on-coast turbines, and that wind turbines often create noise pollution and 
vibrations. Despite the failures in the local scope of this project, on a larger, global scope, wind power has potential to grow and supply large amounts of energy. It provides a useful alternative to fossil fuels. The implications of this exploration are that wind energy can be optimized for high efficiencies and even replace fossil fuels as a source of energy.

\section{CONCLUSION AND RECOMMENDATIONS}

In summary, the different attributes of wind turbines and the wind power formula are explored. The power coefficient is constrained by Betz limit or a theoretical maximum to efficiency of a turbine. Other restrains also exist such as wind velocity and the very design of the wind turbine. These results imply that the design of our wind turbines can be improved on to become even more efficient, however, and to have a higher energy yield. An example of this includes the length of the blades of the wind turbines, where the plateau for their efficiency has yet to be discovered. Currently, larger and higher turbines provide more power output, and the future for even larger turbines with more funding and better technology.

Recommendations for this project would be to experiment with various variables with real life data and trials. It would be more effective for this project to use various data sources to support the claims that are made from physics equations. Additionally, exploring the relationship of kinetic energy in the wind and the power extrapolated by a wind turbine would have aided in explaining efficiency and Betz limit. Finally, Schmitz power coefficient could be explored to add onto the mathematical background of these findings. Questions that are raised from this exploration involve the plateau that has not been reached for the height of rotors and the length of blades, or in general, how large wind turbines can reach. Currently, the higher and larger the turbines generally imply more energy yield. Is there a limit to this concept? How does height and size relate to energy yield and efficiency? Overall, the exploration provides information 
concerning the variables that effect wind energy and gives hope for the future of renewable energy sources.

\section{NOMENCLATURE}

\begin{tabular}{|l|l|c|}
\hline \multicolumn{1}{|c|}{ Variable } & Description & Units \\
\hline$P$ & Power Output & Watts \\
\hline$p$ & Density & $\mathrm{kg} / \mathrm{m}^{3}$ \\
\hline$C_{p}$ & Maximum power coefficient & \\
\hline$A$ & Rotor Swept Area & $\mathrm{m}$ \\
\hline$R$ & Blade Length & $\mathrm{m}$ \\
\hline$V$ & Velocity & $\mathrm{m} / \mathrm{s}$ \\
\hline$v_{1}$ & Wind Velocity Before Turbine & $\mathrm{m} / \mathrm{s}$ \\
\hline$v_{2}$ & Wind Velocity After Turbine & $\mathrm{Watts}$ \\
\hline$P_{0}$ & Maximum Power Output & $\mathrm{rad} / \mathrm{sec}$ \\
\hline$x$ & Number of Blades & \\
\hline$v$ & Speed of Rotor Tip & $\mathrm{m} / \mathrm{s}$ \\
\hline$v^{2}$ Substitution & \\
\hline
\end{tabular}




\section{REFERENCES}

Bakirci, Mehmet, and Sezayi Yılmaz. "Theoretical and Computational Investigations of the Optimal Tip-Speed Ratio of Horizontal-Axis Wind Turbines.” Engineering Science and Technology, an International Journal, vol. 21, no. 6, 2018, pp.1128-1142; doi:10.1016/j.jestch.2018.05.006.

Blackwood, Marisa "Maximum Efficiency of a Wind Turbine," Undergraduate Journal of Mathematical Modeling: One + Two: (2016) Vol. 6: Iss. 2, Article 2.

Carriveau, Rupp. Fundamental and Advanced Topics in Wind Power. InTech, 2011.

Deign, Jason. "How Big Can Wind Turbines Get?" Greentech Media, Greentech Media, 5 Dec. 2016, www.greentechmedia.com/articles/read/how-big-can-wind-turbines get-pretty-damn-big. Kerrigan, Saoirse. "The Scientific Reason Why Wind Turbines Have 3 Blades.” Interesting Engineering, Interesting Engineering, 2 May 2018, interestingengineering.com/the-scientificreason-why-wind-turbines-have-3 blades.

"Renewable Energy and Electricity." World Nuclear Association, World Nuclear Association, May 2019, www.world-nuclear.org/information-library/energy-andthe-environment/renewableenergy-and-electricity.aspx.

"Small Wind Turbines (SWTs) - The Basics." WindEmpowerment, Wind Empowerment, 8 Feb. 2019, windempowerment.org/small-wind-turbines-the-basics/.

Larson, Ron, Robert Hostetler and Bruce Edwards. Calculus. 8th Edition. Boston, MA: Houghton Mifflin Company, 2005.

Spalenka, Josef. "Science Cats! Volume 2." 6 April 2014. The Spalenka Letters. Blog. <http://spalenkaletters.blogspot.com/2014/04/science-cats-volume-2.html〉. 